\title{
The Effect of Goal-Directed Fluid Therapy versus Standard Fluid Therapy on the Cuff Leak Gradient in Patients Undergoing Complex Spine Surgery in Prone Position
}

\author{
Chandrakant Prasad ${ }^{1}$ Nayani Radhakrishna ${ }^{2}$ Mihir Prakash Pandia ${ }^{1}$ Ankur Khandelwal ${ }^{1}$ \\ Gyaninder Pal Singh ${ }^{10}$ Parmod Kumar Bithal ${ }^{1}$
}

${ }^{1}$ Department of Neuroanesthesiology and Critical Care, All India Institute of Medical Sciences, New Delhi, India

2 Department of Anaesthesia, Command Hospital (Eastern

Command), Kolkata, West Bengal, India

Address for correspondence Gyaninder Pal Singh, MD, DM, Department of Neuroanesthesiology and Critical Care, Neurosciences Centre, All India Institute of Medical Sciences, New Delhi 110029, India (e-mail: drsingh_gp@yahoo.co.in).

J Neurosci Rural Pract 2021;12:745-750.

\begin{abstract}
Keywords

- airway edema

- complex spine surgery

- cuff leak gradient

- goal-directed fluid therapy

- prone position

- standard fluid therapy
\end{abstract}

Objective Cuff leak test is an effective and established maneuver to predict airway edema. Standard fluid therapy (SFT) based on conventional monitoring is often associated with postoperative airway edema after complex spine surgeries. We conducted this prospective randomized controlled study to compare the effect of SFT versus goal-directed fluid therapy (GDFT) on the cuff leak gradient (CLG) in patients undergoing complex spine surgery in prone position. Our secondary objectives were to compare the effect of SFT and GDFT on sore throat, hoarseness, and length of intensive care unit (ICU) and hospital stay. Materials and Methods Thirty consecutive American Society of Anesthesiologists physical status I and II patients (18-60 years), of either sex, scheduled for spine surgery in prone position with expected duration of surgery more than 5 hours were included. The patients were randomized into two groups of 15 each. Group $S$ patients $(n=15)$ served as control group and received SFT intraoperatively, while patients in group $G$ $(n=15)$ received GDFT. Standard anesthetic protocol was followed in both the groups. The CLG was defined as the difference between the cuff leak volume (CLV) after intubation $\left(\mathrm{CLV}_{\mathrm{AI}}\right)$ and before extubation $\left(\mathrm{CLV}_{\mathrm{BE}}\right)$.

Statistical Analysis and Results CLG was significantly less in group G (group S, $137.12 \mathrm{~mL}$; group G, $65.52 \mathrm{~mL}$; $p$-value $<0.001$ ). Intravenous fluids, blood loss, and postoperative sore throat were comparatively lesser in group $G$, though not statistically significant. Postoperative hoarseness was significantly lower in group $G$ ( $p$-value $=0.003$ ). Duration of ICU stay in group G ( 19.43 hours) was significantly lower ( $p$-value $=0.009$ ) than group S (24.64 hours), but length of hospital stay was comparable.

Conclusion GDFT significantly reduces airway edema and consequently reduces CLG as compared with SFT in patients undergoing complex spine surgery in prone position. Postoperatively, it also reduces sore throat, hoarseness of voice, and duration of ICU stay. published online September 28, 2021
DOI https://doi.org/ 10.1055/s-0041-1735321. ISSN 0976-3147. (c) 2021. Association for Helping Neurosurgical Sick People. All rights reserved.

This is an open access article published by Thieme under the terms of the Creative Commons Attribution-NonDerivative-NonCommercial-License, permitting copying and reproduction so long as the original work is given appropriate credit. Contents may not be used for commercial purposes, or adapted, remixed, transformed or built upon. (https://creativecommons.org/ licenses/by-nc-nd/4.0/)

Thieme Medical and Scientific Publishers Pvt. Ltd., A-12, 2nd Floor, Sector 2, Noida-201301 UP, India 


\section{Introduction}

Airway edema frequently accompanies prolonged surgery in the prone position, especially when vigorous fluid resuscitation has been performed. ${ }^{1}$ This airway edema may present with postextubation stridor, sore throat, and hoarseness of voice, and carries a high risk of reintubation following tracheal extubation. ${ }^{2}$ Airway edema may be effectively predicted by cuff leak test (CLT) based on cuff leak volume (CLV), which is calculated as the difference between the mean inspiratory tidal volume and the mean expiratory tidal volume when the cuff of the endotracheal tube (ETT) is completely deflated. ${ }^{3,4}$

In routine practice, intraoperative volume replacement is usually guided by static circulatory parameters such as blood pressure, heart rate, or central venous pressure (CVP). However, fluid replacement based on static parameters often leads to volume overload and has been associated with adverse postoperative outcomes. ${ }^{5}$ Goal-directed fluid therapy (GDFT) using cardiac output monitor is becoming popular for fluid management during complex spine surgical procedures. GDFT has been shown to facilitate early postoperative bowel motility, reduced postoperative nausea and vomiting, and early discharge from the hospital. ${ }^{6}$ Therefore, this study was undertaken primarily to compare the effect of standard fluid therapy (SFT) versus GDFT on the cuff leak gradient (CLG) in patients undergoing complex spine surgery in prone position. The secondary objectives were to compare the effect of SFT and GDFT on sore throat, hoarseness, and length of intensive care unit (ICU) and hospital stay. In this study, we hypothesized that airway edema as measured by CLG would be lesser with GDFT as compared with SFT in patients undergoing complex spine surgery.

\section{Materials and Methods}

This prospective randomized controlled study was performed following the approval from the Institute Ethics Committee (Ref. No. IEC/323/5/2016) and written informed consent from the patients. Patients having cardiac, pulmonary, coagulation or renal disorders, morbid obesity, chronic smokers, patients who needed more than one attempts at intubation, patients anticipated for postoperative mechanical ventilation, and those unwilling to participate in the study were excluded. Thirty consecutive American Society of Anesthesiologists (ASA) physical status I and II patients, aged between 18 and 60 years, of either sex, scheduled for complex spine surgery (involving more than three levels of thoracic, lumbar, or thoracolumbar spine) in prone position with expected duration of surgery more than 5 hours, were included. The patients were randomized into two groups of 15 each using computer-generated randomization chart and identical opaque envelopes for concealment. Group $\mathrm{S}$ patients $(n=15)$ served as control group and received SFT intraoperatively, while patients in group $G(n=15)$ received GDFT. In the operating room, standard noninvasive monitors (five-lead electrocardiography, pulse oximetry, and automated noninvasive blood pressure) along with bispectral index
(BIS) were applied to all patients. In both the groups, induction of general anesthesia (GA) was done with $2 \mu \mathrm{g} / \mathrm{kg}$ of fentanyl and 2 to $3 \mathrm{mg} / \mathrm{kg}$ of propofol. Muscle relaxation and intubation of trachea were facilitated by administration of $1 \mathrm{mg} / \mathrm{kg}$ of rocuronium. Adequately sized polyvinylchloride ETT, $7 / 7.5 \mathrm{~mm}$ ID (internal diameter) for females and $8 / 8.5 \mathrm{~mm}$ ID for males, were used and tracheal tube cuff pressure was adjusted to keep at 20 to $25 \mathrm{~cm} \mathrm{H}_{2} \mathrm{O}$. Maintenance of GA was done with oxygen (40\%) and air mixture, sevoflurane (titrated to maintain BIS value between 40 and $60)$, fentanyl $(1 \mu \mathrm{g} / \mathrm{kg} / \mathrm{h})$, and rocuronium $(10 \mu \mathrm{g} / \mathrm{kg} / \mathrm{min})$. The lungs were ventilated intraoperatively with tidal volume of 8 to $10 \mathrm{~mL} / \mathrm{kg}$ and fresh gas flow rate at $2 \mathrm{~L} / \mathrm{min}$. Adjustment of respiratory rate was done to maintain an end-tidal carbon dioxide of 35 to $40 \mathrm{~mm} \mathrm{Hg}$. Five minutes after endotracheal intubation, the inspiratory tidal volume $\left(\operatorname{ITV}_{\mathrm{AI}}\right)$ was noted (average of three readings) from the spirometer of anesthesia machine. Expiratory tidal volume after intubation $\left(\mathrm{ETV}_{\mathrm{AI}}\right)$, average of three readings, was then noted after completely deflating the cuff of ETT. After noting the readings, tracheal cuff was reinflated (cuff pressure; $20-25 \mathrm{~cm}$ $\mathrm{H}_{2} \mathrm{O}$ ) and mechanical ventilation continued. Apart from noninvasive monitoring, invasive radial arterial pressure, CVP in jugular vein, nasopharyngeal temperature, and urine output were also monitored. Normothermia $\left(36-37^{\circ} \mathrm{C}\right)$ was maintained throughout the intraoperative period using forced air warming blanket.

In group $\mathrm{S}$, fluid was administered according to the standard fluid calculation for fasting deficit, evaporation loss, maintenance fluid requirement, replacement of urine output, and blood loss. Further fluid administration was based on the hemodynamic parameters to keep the heart rate (HR) and mean arterial pressure (MAP) within $20 \%$ of the baseline and CVP between 8 and $12 \mathrm{~mm} \mathrm{Hg}$. Group G patients were continuously monitored for cardiac index $(\mathrm{CI})$, stroke volume index, and stroke volume variation (SVV) during intraoperative period using invasive cardiac output monitor (FloTrac/Vigileo, Edwards Lifesciences, Irvine, California, United States). Fluids, vasopressors, or inotropes were administered to keep the goals of $\mathrm{SVV}<12 \%, \mathrm{CI}>2.5 \mathrm{~L} / \mathrm{min} / \mathrm{m}^{2}$, and MAP $>65 \mathrm{~mm} \mathrm{Hg}$. If SVV $>12 \%$, crystalloid bolus of $250 \mathrm{~mL}$ was given over 5 minutes and SVV reassessed after 5 minutes. If MAP was $<65 \mathrm{~mm} \mathrm{Hg}$ and SVV $<12 \%$, then vasopressor (phenylephrine $1 \mu \mathrm{g} / \mathrm{kg}$ bolus) was given intravenously. If $\mathrm{CI}<2.5 \mathrm{~L} / \mathrm{min} / \mathrm{m}^{2}$ with $\mathrm{MAP}<65 \mathrm{~mm} \mathrm{Hg}$ and SVV $<12 \%$, then dobutamine infusion was started. Hemoglobin value less than $8 \mathrm{mg} / \mathrm{dL}$ was considered as transfusion trigger for both the groups and total intraoperative input and output including blood loss were recorded.

Infusion of fentanyl and rocuronium was stopped $\sim 30$ minutes prior to the start of skin closure. Thereafter, maintenance of anesthesia was done with sevoflurane and fentanyl bolus $(0.5 \mu \mathrm{g} / \mathrm{kg})$ as required. After the completion of surgery, the patient was turned supine and sevoflurane was switched off. The averaged inspired tidal volume before extubation $\left(\mathrm{ITV}_{\mathrm{BE}}\right)$ and averaged expired tidal volume before extubation $\left(\mathrm{ETV}_{\mathrm{BE}}\right)$ after tracheal cuff deflation was noted as done in the beginning. Reversal of neuromuscular blockade 
Table 1 Scoring system used for assessment of sore throat and hoarseness ${ }^{7}$

\begin{tabular}{|l|}
\hline Sore throat \\
\hline 0-No sore throat at any time since the operation \\
\hline 1-The patient answered in the affirmative when asked about sore throat (minimal sore throat) \\
\hline 2-The patient complained of sore throat on his/her own (moderate sore throat) \\
\hline 3-The patient is in obvious distress (severe sore throat) \\
\hline Hoarseness \\
\hline 0-No complaint of hoarseness at any time since the operation \\
\hline 1-Minimal change in quality of speech. Patient answers in the affirmative only when enquired about (minimal hoarseness) \\
\hline 2-Moderate change in quality of speech of which the patient complains on his/her own (moderate hoarseness) \\
\hline 3-Gross change in the quality of voice perceived by the observer (severe hoarseness) \\
\hline
\end{tabular}

was done with neostigmine $(50-70 \mu \mathrm{g} / \mathrm{kg}$ ) and glycopyrrolate $(10 \mu \mathrm{g} / \mathrm{kg})$. Extubation of trachea was done in completely awake state.

The tidal volume difference between the $\operatorname{ITV}_{\mathrm{AI}}$ and $\mathrm{ETV}_{\mathrm{AI}}$ was taken as the CLV after intubation $\left(\mathrm{CLV}_{\mathrm{AI}}\right)$. Similarly, tidal volume difference between the $\operatorname{ITV}_{\mathrm{BE}}$ and $\mathrm{ETV}_{\mathrm{BE}}$ was noted as the $\mathrm{CLV}$ before extubation $\left(\mathrm{CLV}_{\mathrm{BE}}\right)$. The $\mathrm{CLG}$ was defined as the difference between the $\mathrm{CLV}_{\mathrm{AI}}$ and $\mathrm{CLV}_{\mathrm{BE}}$.

Postoperatively, all patients were shifted to neurointensive care unit for further management. Any respiratory difficulty and need for reintubation due to airway edema/ stridor in the next 48 hours was noted. All patients were examined for postoperative sore throat and hoarseness of voice 24 hours after the surgery. Appropriate scales were used for assessment of postoperative sore throat and hoarseness (-Table 1). ${ }^{7}$ All patients were followed up in the postoperative period till discharge and the duration of stay in ICU and hospital was noted.

Data were analyzed using Statistical Package for the Social Sciences (SPSS), version 25. Normality testing was done using Shapiro-Wilk's test. Descriptive statistics were determined. Normally distributed or parametric data are presented in the form of mean (standard deviation), whereas data which were not normally distributed or nonparametric data are presented in the form of median (quartile deviation). Unpaired $t$-test and Mann-Whitney's test were used for analysis of parametric and nonparametric data, respectively. Categorical variables were analyzed using the chi-square test/Fisher's exact test. Statistical significance was taken as $p<0.05$.

\section{Results}

Enrollment of 30 patients was done in the study, however, surgery of one patient in group $G$ was postponed due to precipitation of arrhythmia before induction of anesthesia. Therefore, a total of 15 patients in group $S$ and 14 patients in group $G$ were included for analysis ( - Fig. 1). Demographic profile of patients in both the groups were comparable (-Table 2). In both the groups, the CLV between the two phases, that is, $\mathrm{CLV}_{\mathrm{AI}}$ and $\mathrm{CLV}_{\mathrm{BE}}$ were comparable. However, CLG was significantly less in group G (group S, $137.12 \mathrm{~mL}$; group G, $65.52 \mathrm{~mL}$; $p$-value $<0.001$ ). Intake of intravenous fluids, blood loss, and postoperative sore throat were comparatively lesser in group $G$, though not statistically significant. Intraoperative mean HR, MAP, BIS, and CVP were within normal limits and comparable between the two groups (-Fig. 2). Both the groups had comparable surgical and anesthesia duration. Incidence of postoperative hoarseness of voice was significantly lower in group $G$ ( $p$-value $=0.003$ ). Length of ICU stay in group $\mathrm{G}$ (19.43 hours) was significantly lower ( $p$-value $=0.009)$ than group $S$ (24.64 hours), but length of hospital stay was comparable (-Table 3 ). Reintubation was not required in any patient in our study.

\section{Discussion}

Prone position with attendant acute venous congestion of head and neck precipitated by excessive fluids administration can result in facial and upper airway edema which in turn can lead to delayed extubation, postoperative stridor, sore throat, hoarseness of voice, and reintubation. ${ }^{1,2}$ CLT is an objective assessment of airway edema and has been used extensively for prediction of postextubation stridor in prolonged mechanically ventilated patients in the ICU setting. ${ }^{3,4}$ However, this is the first study that has compared the effect of SFT and GDFT on CLG in patients undergoing complex spine surgery in prone position. In our study, CLG was significantly lesser in group $G$ as compared with group $S$. Since the duration of surgery and anesthesia in the prone position was comparable between the two groups and there was no direct trauma to airway to any of the patient during laryngoscopy and intubation, the difference in airway edema and consequent CLG between the two groups is most likely attributed to intraoperative fluid administration. In our study, GDFT resulted in lesser fluid administration as compared with SFT. Our study correlates well with multiple other studies which have shown that GDFT results in lesser volume of fluid administered and lower net fluid balance, thus, causing less tissue edema. ${ }^{8,9}$ However, our study differs in two main aspects. First, we utilized CLT for evaluating tissue edema unlike other studies which have utilized extravascular lung water for diagnosing tissue edema. ${ }^{8,10}$ Second, our study included patients who underwent spine surgery where 


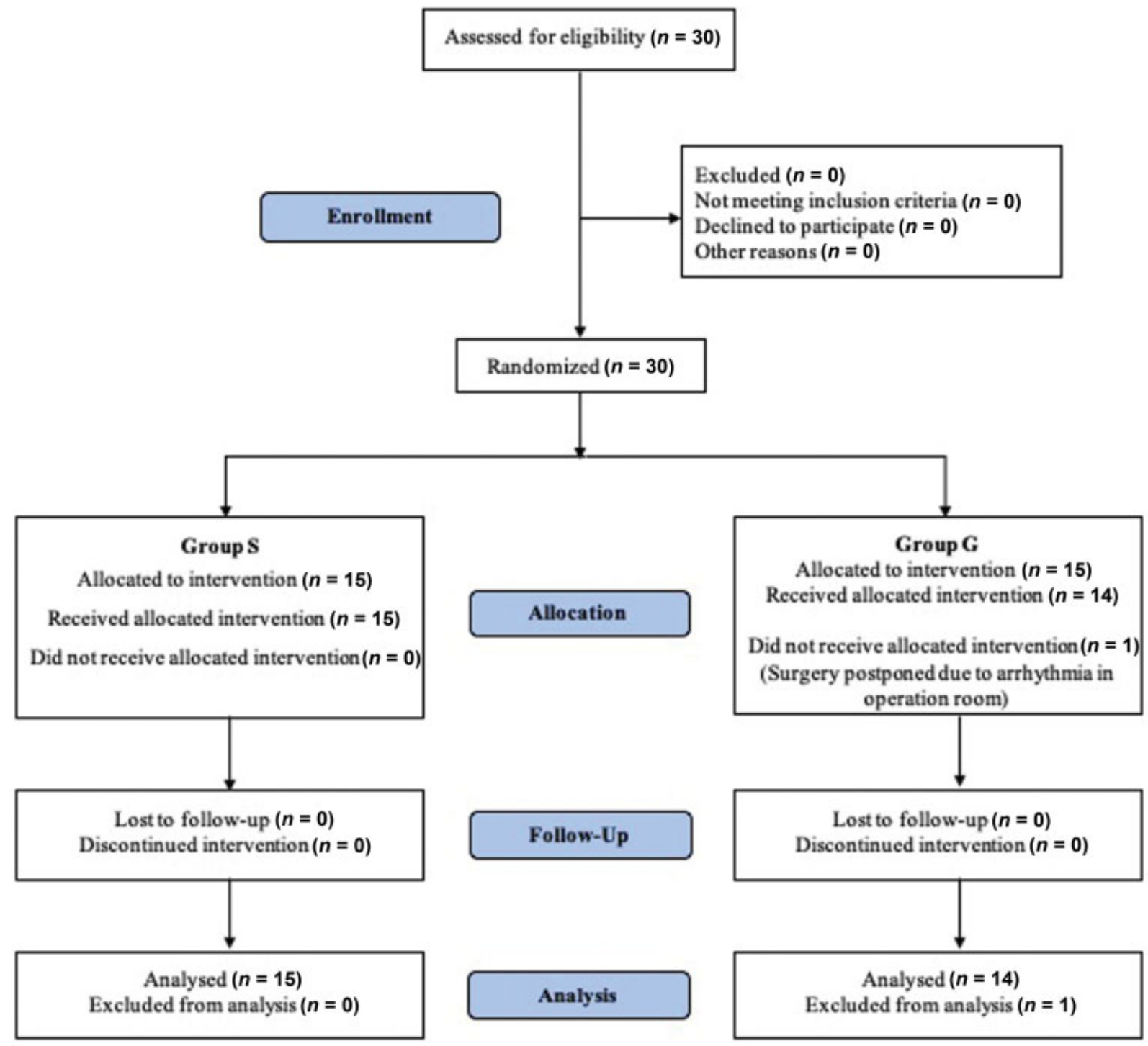

CONSORT Flow Diagram

Fig. 1 CONSORT flow diagram.

Table 2 Comparison of demographic parameters between the two groups

\begin{tabular}{|c|c|c|c|c|}
\hline \multicolumn{2}{|l|}{ Parameters } & Group S & Group G & $p$-Value \\
\hline \multicolumn{2}{|l|}{ Age $(y)^{a}$} & 34.93 (11.79) & $36.71(16.22)$ & 0.756 \\
\hline \multirow[t]{2}{*}{ Gender } & Male $(N)$ & 9 & 8 & 0.808 \\
\hline & Female $(N)$ & 6 & 6 & 1 \\
\hline \multicolumn{2}{|l|}{ Weight $(\mathrm{kg})^{\mathrm{a}}$} & $62.29(10.48)$ & $63.43(16.94)$ & 0.852 \\
\hline \multicolumn{2}{|l|}{ Height $(\mathrm{cm})^{\mathrm{a}}$} & $164.71(7.23)$ & $166.86(6.86)$ & 0.475 \\
\hline \multirow[t]{2}{*}{ ASA status } & $I(N)$ & 10 & 9 & 0.819 \\
\hline & II $(N)$ & 5 & 5 & 1 \\
\hline
\end{tabular}

Abbreviations: ASA, American society of Anesthesiologists; N, number.

${ }^{a}$ Mean (standard deviation), $p$-value $<0.05$ significant. 

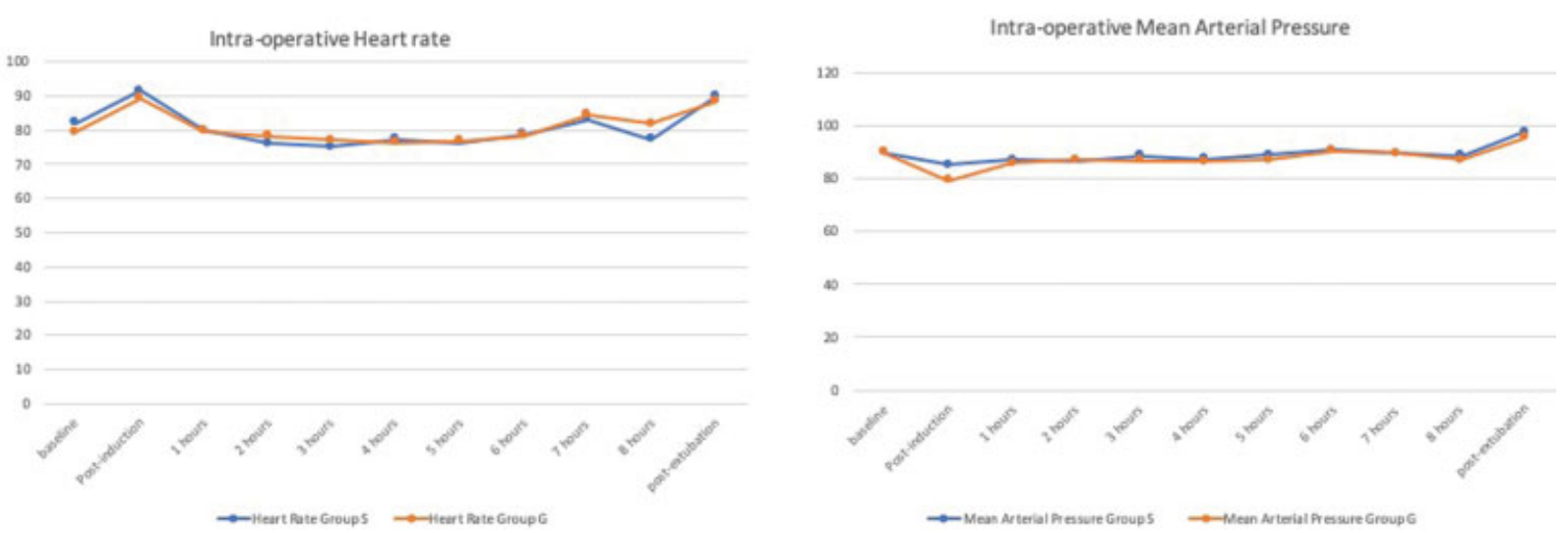

Fig. 2 Trends of intraoperative heart rate and mean arterial pressure between the two groups.

Table 3 Comparison of various intraoperative and postoperative parameters between the two groups

\begin{tabular}{|l|l|l|l|}
\hline Parameters & Group S & Group G & $p$-Value \\
\hline $\mathrm{CLV}_{\text {AI }}(\mathrm{mL})$ & $244.55(57.78)$ & $216.31(46.35)$ & 0.104 \\
\hline $\mathrm{CLV}_{\mathrm{BE}}(\mathrm{mL})$ & $107.43(52.90)$ & $150.79(47.35)$ & 0.061 \\
\hline $\mathrm{CLG}(\mathrm{mL})$ & $137.12(54.42)$ & $65.52(22.41)$ & 0.000 \\
\hline Crystalloid (mL) & $3,142.86(1,179.12)$ & $2,657.14(671.07)$ & 0.235 \\
\hline Colloid $(\mathrm{mL})$ & $392.86(349.65)$ & $357.14(305.62)$ & 0.818 \\
\hline Blood loss $(\mathrm{mL})^{\mathrm{a}}$ & $325(187.5)$ & $300(100)$ & 0.595 \\
\hline Heart rate (beats/min) & $81.37(9.35)$ & $80.17(11.25)$ & 0.801 \\
\hline Mean arterial pressure (mm Hg) & $88.26(8.56)$ & $87.62(4.75)$ & 0.823 \\
\hline Bispectral index value (number) & $42.96(1.78)$ & $43.62(1.49)$ & 0.366 \\
\hline Central venous pressure (mm Hg) & $9.84(0.39)$ & $9.67(0.64)$ & 0.565 \\
\hline Duration of surgery (min) & $308.93(125.50)$ & $304.64(76.70)$ & 0.925 \\
\hline Duration of anesthesia (min) & $410.36(123.44)$ & $396.41(63.80)$ & 0.736 \\
\hline Sore throat score & $0.79(0.58)$ & $0.43(0.51)$ & 0.136 \\
\hline Hoarseness of voice score & $0.57(0.51)$ & $0.07(0.27)$ & 0.003 \\
\hline Length of ICU stay (h) & $24.64(6.20)$ & $19.43(4.80)$ & 0.009 \\
\hline Length of hospital stay (d) & $3.64(0.74)$ & $3.71(0.73)$ & 0.793 \\
\hline
\end{tabular}

Abbreviations: $\mathrm{CLV}_{\mathrm{Al}}$, cuff leak volume after intubation; $\mathrm{CLV}_{\mathrm{BE}}$, cuff leak volume before extubation; $\mathrm{CLG}$, cuff leak gradient; ICU, intensive care unit. Note: All parameters are expressed as mean (standard deviation).

${ }^{a}$ Expressed as median (quartile deviation), $p$-value $<0.05$ significant.

the effect of physiological fluid shift is minimal unlike abdominal surgeries which are characterized by third space loss and significant fluid shifts. ${ }^{8,9}$ As such, tissue edema in our study is primarily a reflection of net fluid balance.

In our study, GDFT resulted in lower CLG and lesser airway edema as compared with SFT. This eventually translated clinically into lower postoperative mean scores of sore throat (though statistically insignificant), hoarseness of voice, and reduced duration of ICU stay. A recent meta-analysis consisting of 29 studies and 2,099 patients found that intraoperative GDFT was associated with significantly less morbidity and duration of ICU stay. ${ }^{11}$ Though few studies have shown that GDFT is associated with shorter duration of hospital stay compared with SFT, ${ }^{11,12}$ in our study, the total duration of hospital stay was comparable. This could be a result of multiple factors other than GDFT. Moreover, although hoarseness incidence was higher in group S, none of the patients required reintubation and they were managed conservatively. Our study correlates well with previous studies by Bacchin et al and Che et al who found that patients who received GDFT in spine surgery had similar duration of hospital stay as compared with controls despite fewer postoperative complications and lesser duration of ICU stay. ${ }^{13,14}$

In our study, we included only ASA physical status I and II patients. Our results are consistent with previous studies which have shown that outcome benefits related to the use of intraoperative GDFT are not limited to high-risk patients. ${ }^{9,15}$ In our study, despite the administration of lesser volume of 
fluids in GDFT group, both the groups had comparable MAP. This is attributed to SVV-guided precise evaluation of volume status in GDFT group. With regard to blood loss, patients who received GDFT had relatively less blood loss, though statistically comparable with SFT. On the contrary, patients who received GDFT in the study by Bacchin et al had significantly lesser blood loss as compared with controls. ${ }^{13}$ This difference could be due to the variable spine pathology and surgical experience of different surgeons in our study.

In our study, there was a decreasing trend in the use of intraoperative fluid in the GDFT group which however did not reach statistical significance probably due to the transfusion of less volume of fluid in both groups. Nevertheless, there was a significant difference in the CLG and the GDFT group had less airway edema. This finding can be more significant in surgeries where large intraoperative fluid volume replacements occurs.

Our study has few limitations. First, the sample size is relatively small and warrants more studies with larger sample size. Second, the technique of CLT involves deflating the cuff which might cause aspiration. Though we cannot completely exclude microaspiration, none of the patients had clinical findings suggestive of aspiration in the postoperative period. Third, the utilization of cardiac output monitor involves extra cost; however, the benefit involved with the use of this monitor clearly outweighs the cost involved.

\section{Conclusion}

GDFT significantly reduces airway edema and consequently reduced the CLG as compared with SFT in patients undergoing complex spine surgery in prone position. Postoperatively, it also reduces sore throat, hoarseness of voice, and duration of ICU stay.

\section{Note}

The study was approved by the Institute Ethics Committee of All India Institute of Medical Sciences, New Delhi vide letter Ref. No. IEC/323/5/2016.

\section{Authors' Contributions}

P.K.B., M.P.P., and G.P.S. were involved in concept/design of the work. C.P., N.R., and A.K were involved in acquisition, analysis, or interpretation of data. A.K., C.P., and N.R. contributed in the drafting of the manuscript. G.P.S., M.P.P., and P.K.B. helped in the revision of the manuscript. C.P., N.R., A.K., G.P.S., M.P.P., and P.K.B. approved the final version of the submitted manuscript. All the authors were responsible for all aspects of the work including its accuracy and integrity.

Funding

None.
Conflict of Interest

None declared.

\section{References}

1 Anastasian ZH, Gaudet JG, Levitt LC, Mergeche JL, Heyer EJ, Berman MF. Factors that correlate with the decision to delay extubation after multilevel prone spine surgery. J Neurosurg Anesthesiol 2014;26(02):167-171

2 Cooper RM, Khan S. Extubation and reintubation of the difficult airway. In: Hagberg CA, eds. Benumof and Hagberg's Airway Management. 3rd edition. Philadelphia, Pa: WB Saunders; 2013:1018-46.e7

3 Miller RL, Cole RP. Association between reduced cuff leak volume and postextubation stridor. Chest 1996;110(04):1035-1040

4 Zhou T, Zhang HP, Chen WW, et al. Cuff-leak test for predicting postextubation airway complications: a systematic review. J Evid Based Med 2011;4(04):242-254

5 Brandstrup B, Tønnesen H, Beier-Holgersen R, et al; Danish Study Group on Perioperative Fluid Therapy. Effects of intravenous fluid restriction on postoperative complications: comparison of two perioperative fluid regimens: a randomized assessor-blinded multicenter trial. Ann Surg 2003;238(05):641-648

6 Gan TJ, Soppitt A, Maroof M, et al. Goal-directed intraoperative fluid administration reduces length of hospital stay after major surgery. Anesthesiology 2002;97(04):820-826

7 Bagchi D, Mandal MC, Das S, Sahoo T, Basu SR, Sarkar S. Efficacy of intravenous dexamethasone to reduce incidence of postoperative sore throat: a prospective randomized controlled trial. J Anaesthesiol Clin Pharmacol 2012;28(04):477-480

8 Hasanin A, Mourad KH, Farouk I, et al. The impact of goal-directed fluid therapy in prolonged major abdominal surgery on extravascular lung water and oxygenation: a randomized controlled trial. Open Access Maced J Med Sci 2019;7(08):1276-1281

9 Sujatha PP, Nileshwar A, Krishna HM, Prasad SS, Prabhu M, Kamath SU. Goal-directed vs traditional approach to intraoperative fluid therapy during open major bowel surgery: is there a difference? Anesthesiol Res Pract 2019;2019:3408940

10 Haas S, Eichhorn V, Hasbach T, et al. Goal-directed fluid therapy using stroke volume variation does not result in pulmonary fluid overload in thoracic surgery requiring one-lung ventilation. Crit Care Res Pract 2012;2012:687018

11 Rollins KE, Lobo DN. Intraoperative goal-directed fluid therapy in elective major abdominal surgery: a meta-analysis of randomized controlled trials. Ann Surg 2016;263(03):465-476

12 Li P, Qu LP, Qi D, et al. Significance of perioperative goal-directed hemodynamic approach in preventing postoperative complications in patients after cardiac surgery: a meta-analysis and systematic review. Ann Med 2017;49(04):343-351

13 Bacchin MR, Ceria CM, Giannone S, et al. Goal-directed fluid therapy based on stroke volume variation in patients undergoing major spine surgery in the prone position: a cohort study. Spine 2016;41(18):E1131-E1137

14 Che L, Zhang XH, Li X, Zhang YL, Xu L, Huang YG. Outcome impact of individualized fluid management during spine surgery: a before-after prospective comparison study. BMC Anesthesiol 2020;20(01):181

15 Ramsingh DS, Sanghvi C, Gamboa J, Cannesson M, Applegate RL II. Outcome impact of goal directed fluid therapy during high risk abdominal surgery in low to moderate risk patients: a randomized controlled trial. J Clin Monit Comput 2013;27 (03):249-257 